\title{
Treatment of oily wastewater from cold-rolling mill through coagulation and integrated membrane processes
}

\author{
Xue-Ni Cheng, Yan-Wen Gong ${ }^{\dagger}$ \\ College of Chemistry, Chemical and Environmental Engineering, Henan University of Technology, Zhengzhou 450001, China
}

\begin{abstract}
The feasibility of applying coagulation-integrated microfiltration (MF) as a pretreatment for an ultrafiltration (UF) feed in oily wastewater treatment was investigated. The effects of different coagulants on oil removal rates from wastewater were studied. The maximum oil removal rate of $82 \%$ was obtained after coagulation with $130 \mathrm{mg} / \mathrm{L}$ of polyaluminium chloride (PAC). UF flux reached $95 \mathrm{~L} /\left(\mathrm{m}^{2} \cdot \mathrm{h}\right)$ with coagulation-integrated $\mathrm{MF}$ as pretreatment. This value was 2.5 times higher than that flux obtained without pretreatment. The value of UF flux increased as the transmembrane pressure (TMP) and cross-flow velocity (CFV) of the UF module increased. UF flux gradually increased when TMP and CFV exceeded $0.4 \mathrm{MPa}$ and $3 \mathrm{~m} / \mathrm{s}$, respectively, because of concentration polarization and membrane fouling stabilization. Chemical oxygen demand reduction and oil removal rate reached $95.2 \%$ and $98.5 \%$, respectively, during integrated membrane processing with a PAC concentration of $130 \mathrm{mg} / \mathrm{L}$, TMP of $0.4 \mathrm{MPa}$, and CFV of $3 \mathrm{~m} / \mathrm{s}$ for UF. In addition, sequentially cleaning the fouling membrane with $\mathrm{NaOH}$ and $\mathrm{HNO}_{3}$ aqueous solutions caused UF flux to recover to $90 \%$. These encouraging results suggested that the hybrid integrated membrane process-based coagulation and MF + UF are effective approaches for oily wastewater treatment.
\end{abstract}

Keywords: Coagulation, Microfiltration, Oily wastewater, Ultrafiltration

\section{Introduction}

The cold-rolling industry generates a considerable amount of oily wastewater, which contains iron pin, lubricating oil, surfactants, and other pollutants [1,2]. Directly discharging oily wastewater into the environment has negative environmental and ecological impacts. Therefore, numerous chemical and physical technologies, such as coagulation, flotation, gravity, and biodegradation, have been employed to remediate oil-contaminated wastewater [1, 3]. Nevertheless, these conventional methods consume high amounts of energy while exhibiting poor removal efficiency. The low removal rates of these methods are particularly pronounced when used to remove low concentrations of finely dispersed oil droplets from wastewater [3, 4]. Membrane separation technology offers high oil removal efficiency and a facile operational process [5-7].

In general, oil-water separation is significantly affected by the physical and chemical properties of the separation membrane and the conditions of the process. Ohya et al. [8] investigated the effects of average pore size on oil-water emulsion separation with a microfiltration (MF) membrane. The filtration mechanism at the initial stage of the treatment process could be explained by three types of blocking filtration models, which are constructed on the basis of the average pore size of the membrane. The pore size of the membrane should be selected in accordance with oil droplet size to reduce membrane fouling during operation. Hua et al. [9] performed a crossflow MF process using a ceramic $\left(\alpha-\mathrm{Al}_{2} \mathrm{O}_{3}\right)$ membrane with $50 \mathrm{~nm}$ pore size to treat oily wastewater (oil concentration $\approx 500 \mathrm{ppm}$ ). The TOC removal efficiencies of the process exceeded $92 \%$ under all experimental conditions. Lobo et al. [10] studied the effects of crossflow velocity (CFV) and $\mathrm{pH}$ on an ultrafiltration (UF) module for emulsion separation with a tubular ceramic membrane under a transmembrane pressure (TMP) range of 0.05-0.4 $\mathrm{MPa}$. They concluded that permeate flux and chemical oxygen demand retention (CODcr) decreased drastically under low $\mathrm{pH}$ values.

The application of MF and UF in oily water treatment is mainly limited by the fouling (i.e., the severe decline in flux with operation time through the nonspecific adsorption of oil droplets on membrane surfaces and pores) encountered by these processes [7-10]. The antifouling performance of membranes has been improved through structural modification or process optimization [7-8]. In
This is an Open Access article distributed under the terms of the Creative Commons Attribution Non-Commercial License (http://creativecommons.org/licenses/by-nc/3.0/) which permits unrestricted non-commercial use, distribution, and reproduction in any medium, provided the original work is properly cited.

Copyright (C) 2018 Korean Society of Environmental Engineers
Received November 3, 2016 Accepted December 31, 2017

${ }^{\dagger}$ Corresponding author

Email: ywgong123@163.com

Fax: +86-371-67756718

ORCID: 0000-0002-5046-6250 
addition, hydrophilic additives, such as hydrophilic polymers, amphiphilic copolymers, and inorganic nanoparticles, have been introduced to enhance the flux and antifouling properties of membranes. Rajasekhar et al. [11] studied oil-water (1,000 ppm) separation using UF membranes based on novel PVDF and amphiphilictri-block copolymer blends. The modified membrane obtained a water flux that is approximately 2.5 times higher than that of the neat PVDF membrane and maintained 99\% oil rejection. Yuliwati and Ismail [12] used titanium dioxide $\left(\mathrm{TiO}_{2}\right)$ nanoparticles as pore-forming and hydrophilic additives to prepare a PVDF UF membrane. At 1.95 wt $\% \mathrm{TiO}_{2}$ concentration, the membrane showed $82.5 \mathrm{~L} /\left(\mathrm{m}^{2} \cdot \mathrm{h}\right)$ maximum flux and $98.83 \%$ rejection of oily wastewater.

Different separation processes are used for each kind of specific oil/water $(\mathrm{O} / \mathrm{W})$ mixture in accordance with the physical nature of the oil, total oil content, and chemical nature of other components. In many case, the combination of two or more separation techniques is required to increase separation efficiencies. The application of destabilization/evaporation and UF-combined processes, UF and activated carbon hybrid processes, and combined UF and bipolar electro-chemical reactor processes in O/W separation has been studied [13-15]. These integrated processes have shown long-term operational stability and are suitable for $\mathrm{O} / \mathrm{W}$ emulsion treatment.

This work investigated the feasibility of applying a hybrid process that is based on coagulation and a two-stage membrane process with MF + UF in oily wastewater treatment. Wastewater containing micron- or submicron-sized droplets has to be de-emulsified prior to treatment to reduce membrane fouling. Coagulation is a simple pretreatment method for oily wastewater. Oil droplets tend to form large oil globules because of the electrostatic and adsorption effects of coagulants. Thus, large oil globules could be separated easily through the MF + UF process. This work aims to investigate the technical feasibility of coagulation with MF + UF process for the treatment of emulsion wastewater and to provide a superior hybrid membrane process for oily wastewater treatment.

\section{Methods}

\subsection{Materials and Experiment}

Oily wastewater was collected from Heli Metal Rolling Company (Anyang, Henan, China). The precise formulation of the oily wastewater is proprietary. The wastewater contains a mixture of mineral oils and several additives, such as emulsifiers, stabilizers, biocides, and corrosion inhibitors. The wastewater had an oil concentration of approximately $550 \mathrm{mg} / \mathrm{L}$, COD of $6,500 \mathrm{mg} / \mathrm{L}$, a $\mathrm{pH}$ value of 7.2, and turbidity of 1,100 NTU. The size of the oil droplets was measured through laser-light scattering (LS-POP-9, Zhuhai OMEC Instruments Co., Ltd., China) and ranged from $0.02 \mu \mathrm{m}$ to $4 \mu \mathrm{m}$ with an average size of $0.23 \mu \mathrm{m}$.

A schematic of the experimental setup is shown in Fig. 1. Raw wastewater collected from the plant was coagulated for $40 \mathrm{~min}$. A certain amount of coagulant was added to the wastewater at $35^{\circ} \mathrm{C}$. The mixture was stirred at $100 \mathrm{r} / \mathrm{min}$ for $2 \mathrm{~min}$ and precipitated through gravity for $40 \mathrm{~min}$. After coagulation, the supernatant was removed, and the remaining aqueous phase was sent to MF and UF modules. The material of the MF was ceramic membrane

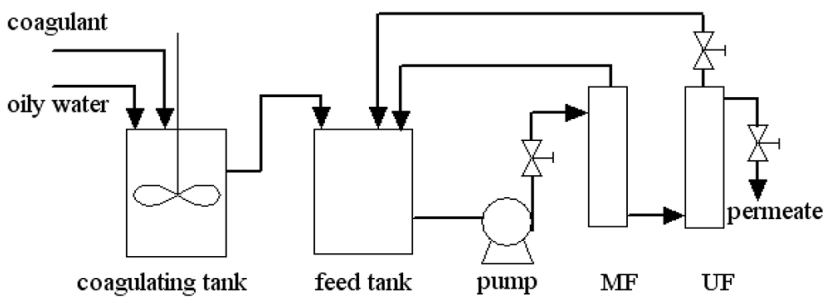

Fig. 1. Schematic of the experimental setup.

with the pore size of $0.2 \mu \mathrm{m}$ and that of the UF was PVDF (cutoff $=500 \mathrm{kDa}$ ). Experiments were performed under crossflow filtration conditions, and temperature was maintained at $35^{\circ} \mathrm{C}$.

After each UF was performed, the membrane module was cleaned through the following steps: (1) Rinsing with $\mathrm{NaOH}$ aqueous solution for $10 \mathrm{~min}$. (2) Rinsing with water for $5 \mathrm{~min}$. (3) Rinsing with $\mathrm{HNO}_{3}$ aqueous solution for 10 min. (4) Rinsing with water for $5 \mathrm{~min}$.

Oil concentration in water was determined through UV-vis spectroscopy at $270 \mathrm{~nm}$ [11]. CODcr was determined through potassium dichromate oxidation method. Water turbidity was determined with the turbidity meter WQ770-B. The flux $J$ was defined as Eq. (2).

$$
J=\frac{V}{A \cdot \Delta t}
$$

where $V$ is the volume of permeated water, $A$ is the membrane area, and $\Delta t$ is the permeation time.

\section{Results and Discussion}

\subsection{Pretreatment by Coagulation}

Polyaluminium chloride (PAC), polyferric sulfate (PFS), and polyacrylamide (PAM) were used as coagulants to destabilize oily wastewater. The effects of coagulant type on oil removal efficiency are shown in Fig. 2. PAC and PFS were more effective than PAM for destabilization. Treatment with $150 \mathrm{mg} / \mathrm{L}$ of PAC decreased the oil content of the wastewater by $83 \%$. Coagulation significantly

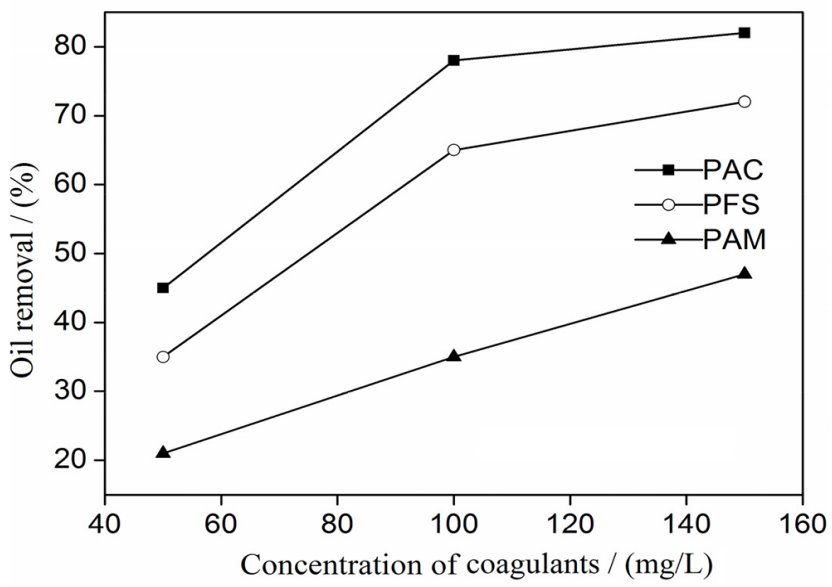

Fig. 2. Effects of coagulants on oil removal rate. 
decreased absolute zeta potential values, and neutrality was approximated. A free oil film formed at the emulsion surface after coalescence. Similar results have been reported in the literature [16, 17]. The addition of excess coagulants is uneconomical because it does not improve coagulation effects. Thus, PAC was used as the coagulant at the concentration of $130 \mathrm{mg} / \mathrm{L}$ for the other tests.

\subsection{Effects of Pretreatment Process on UF Flux}

Pretreatment reduces membrane fouling and has an important role in the efficiency of membrane separation [13]. Wastewater was coagulated with $130 \mathrm{mg} / \mathrm{L}$ of PAC for $40 \mathrm{~min}$ and then pretreated through MF. UF flux values obtained through coagulation integrated with MF, MF only, and coagulation only as a pretreatment are shown in Fig. 3. A shown in Fig. 3, the maximum UF flux was obtained with coagulation integrated with $\mathrm{MF}$ as a pretreatment at any filtration time-point. For example, after $50 \mathrm{~min}$ of filtration, UF flux reached approximately $95 \mathrm{~L} /\left(\mathrm{m}^{2} \cdot \mathrm{h}\right), 85 \mathrm{~L} /\left(\mathrm{m}^{2} \cdot \mathrm{h}\right)$, and 72 $\mathrm{L} /\left(\mathrm{m}^{2} \cdot \mathrm{h}\right)$ with coagulation integrated with $\mathrm{MF}$, coagulation alone, or MF alone as a pretreatment, respectively. The UF flux obtained through coagulation integrated with $\mathrm{MF}$ as a pretreatment was 2.5 times higher than that obtained through coagulation without pretreatment. The surfaces of oil droplets are covered by an electric double layer with a negative charge. The electrostatic interactions of PAC disrupted the stability of oil droplets and other suspended particles. Therefore, aggregation was enhanced by the absence of the net charge of oil droplets and suspended matter. In addition, oil droplets were easily separated through sedimentation and MF. These results revealed that the proposed coagulation process with $\mathrm{PAC}$ and MF is an effective pretreatment for the UF feed.

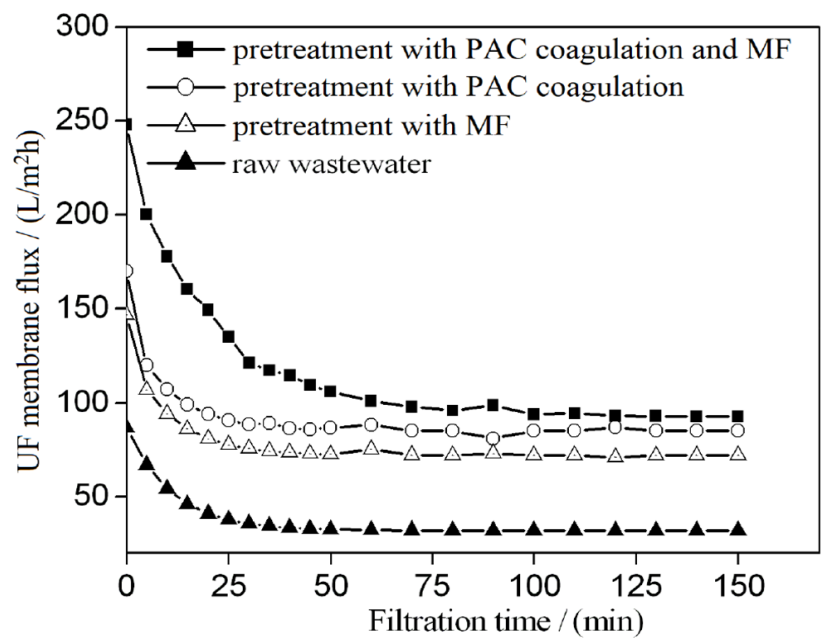

Fig. 3. Effects of pretreatment on UF flux under 0.4 MPa of TMP and $3 \mathrm{~m} / \mathrm{s}$ of CFV.

\subsection{Effects of TMP on UF Flux}

UF flux as a function of filtration time under different TMPs is shown in Fig. 4. UF flux rapidly initially declined and then gradually declined with every increment in TMP. Concentration polarization and gel layer formation occurred as soon as filtration began, causing UF flux to decrease rapidly. Subsequently, a compact and ordered

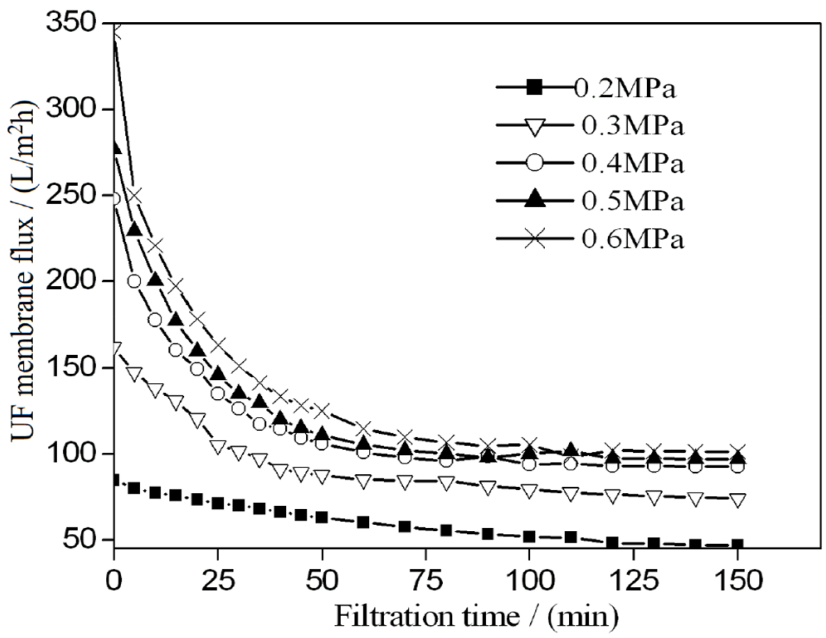

Fig. 4. Effects of TMP on UF flux under $3 \mathrm{~m} / \mathrm{s}$ of CFV.

deposit progressively formed from the outlet to the inlet of the membrane device. This effect caused the flux to gradually decline. Compared with that under the TMP of $0.2 \mathrm{MPa}$, flux declined sharply at the beginning of filtration under the TMP range of $0.3 \mathrm{MPa}$ to 0.6 MPa. Moreover, flux rate decreased slowly after $30 \mathrm{~min}$. These findings indicated that under high TMP, some of the oil droplets adsorbed on the membrane surface or were embedded in the membrane pore. These effects caused the permeate flux to decrease quickly at high TMP. Flux declined slightly after $60 \mathrm{~min}$ because the fouling layer resistance on the membrane stabilized. At long operation times, the flux appeared to approach a nearly constant value. Membrane cleaning failed to restore the flux to its original value when the pressure exceeded 0.6 MPa. The operation pressure was set at $0.4 \mathrm{MPa}$ for other UF experiments.

\subsection{Effects of CFV on UF Flux}

CFV highly influences membrane fouling $[8,18]$. The permeate flux of UF at different CFVs is shown in Fig. 5. The permeate flux increased with increasing CFV. The flux increased significantly

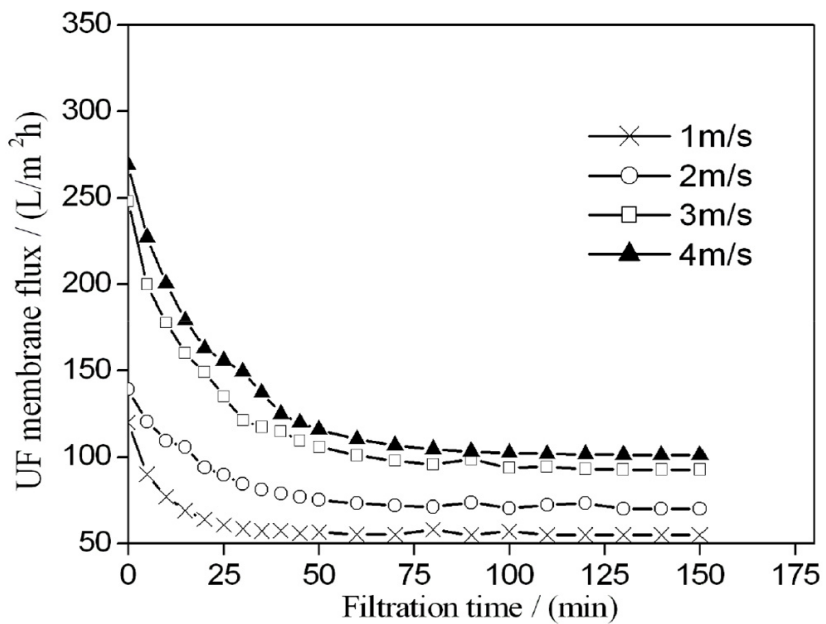

Fig. 5. Effects of CFV on UF flux under 0.4 MPa of TMP. 
Table 1. Quality of UF Permeates

\begin{tabular}{cccr}
\hline & \multicolumn{3}{c}{ TMP/MPa } \\
\cline { 2 - 4 } & $\mathbf{0 . 2}$ & $\mathbf{0 . 4}$ & $\mathbf{0 . 6}$ \\
\hline Oil concentration/mg/L & $8.2 \pm 0.9$ & $8.4 \pm 0.8$ & $8.3 \pm 1$ \\
NTU & $5 \pm 1$ & $5 \pm 1$ & $5 \pm 1$ \\
CODcr/mg/L & $302 \pm 15$ & $310 \pm 10$ & $315 \pm 12$ \\
\hline
\end{tabular}

as CFV increased from $1 \mathrm{~m} / \mathrm{s}$ to $4 \mathrm{~m} / \mathrm{s}$. As expected, high CFV decreased concentration polarization and fouling layer thickness, thus decreasing filtration resistance. Considering the effect of velocity on membrane flux and energy consumption, the membrane surface velocity was set at $3 \mathrm{~m} / \mathrm{s}$.

Table 1 presents the quality of UF permeates. The oil content of the effluent was less than $10 \mathrm{mg} / \mathrm{L}$, and oil removal efficiency exceeded 98.5\% after UF treatment. TMP had a negligible effect on wastewater oil concentration. Oil droplet size may be the main factor that affects UF permeates. The sizes of UF pores are smaller than those of oil droplets. Therefore, turbidity and oil concentration negligibly changed with increasing TMP. These results also showed that oil and colloidal particles were effectively removed from wastewater. Water turbidity decreased to $99 \%$, and CODcr decreased by $95.2 \%$.

\subsection{Membrane Cleaning}

The effects of membrane cleaning are shown in Fig. 6. The decrease in flux to $60 \%$ after $60 \mathrm{~min}$ of filtration time with the UF membrane could be mainly attributed to the absorption of oil droplets on mfiltration time with the UF membrane could be mainly attributed to the absorption of oil droplets on membrane pores and surfaces. Adsorbed oil blocked the membrane pores and increased membrane resistance during the operation. Hence, membrane cleaning is important to improve the efficiency of the pretreatment. Inorganic detergents were used to clean the fouling layer from membranes because organic detergent would increase COD and could change the interfacial tension between the membrane and wastewater. These effects would cause further membrane fouling. UF flux recovered to $90 \%$ after 10 min of membrane cleaning with $\mathrm{NaOH}$

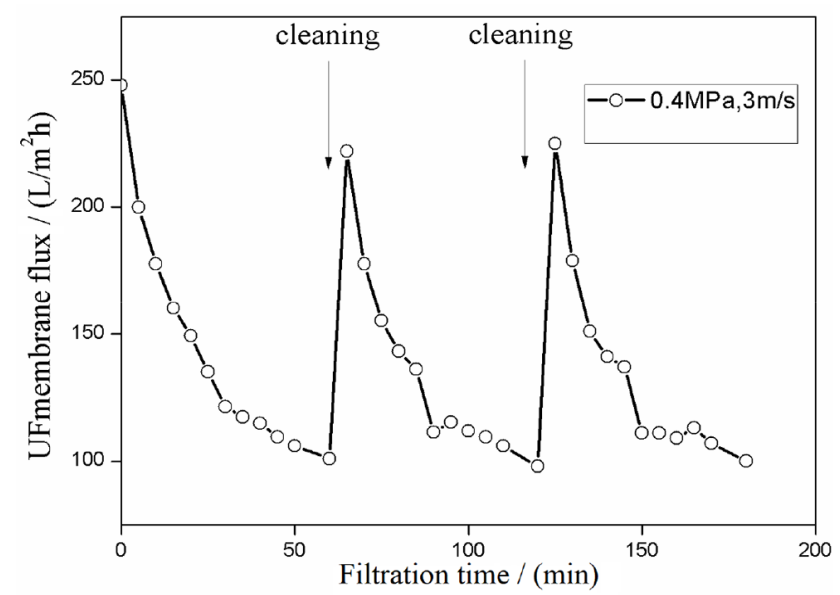

Fig. 6. Effects of membrane cleaning on UF flux. and $\mathrm{HNO}_{3}$ aqueous solutions. Inorganic cleaners also had good removal efficiency for insoluble inorganic, organic, and colloidal pollutants. This finding indicated that the UF membrane could be cleaned with $\mathrm{NaOH}$ and $\mathrm{HNO}_{3}$ aqueous solutions.

\section{Conclusions}

Experimental studies on the treatment of oily wastewater through a hybrid-integrated membrane process based on coagulation and MF + UF were conducted. The optimal operation conditions are as follows: Coagulant concentration of $130 \mathrm{mg} / \mathrm{L} \mathrm{PAC,} \mathrm{TMP} \mathrm{of}$ $0.4 \mathrm{MPa}$, and CFV of $3 \mathrm{~m} / \mathrm{s}$. The oil removal rate and CODcr reduction rate of the process were $98.5 \%$ and $95.2 \%$, respectively, under the optimized conditions. Furthermore, the quality of UF permeates met the local standards for sewage treatment $(<10 \mathrm{mg} / \mathrm{L}$ of oil content and $<500 \mathrm{mg} / \mathrm{L}$ of COD). Cleaning the fouling membrane with $\mathrm{NaOH}$ and $\mathrm{HNO}_{3}$ aqueous solutions led to the UF flux recovery of $90 \%$.

\section{Acknowledgments}

The authors are grateful for the financial support from the Henan University of Technology Fund (No.10XZZ017). The authors also thank the financial support from Xinlu chemical company.

\section{References}

1. Zhang YH, Gan FX, Li M, Li J, Li SQ, Wu SH. New integrated processes for treating cold-rolling mill emulsion wastewater. J. Iron Steel Res. Int. 2010;17:32-35.

2. Zhang YH, Gan FX, Li M, Wang DH, Huang ZM, Gao YP. Treatment of reused comprehensive wastewater in iron and steel industry with electrosorption technology. J. Iron Steel Res. Int. 2011;18:37-42.

3. Jamaly S, Giwa A, Hasan SW. Recent improvements in oil wastewater treatment: Progress, challenges, and future opportunities. J. Environ. Sci. 2015;37:15-30.

4. Chakrabarty B, Ghoshal AK, Purkait MK. Cross-flow ultrafiltration of stable oil in water emulsion using polysulfone membranes. Chem. Eng. J. 2010;165:447-456.

5. Duong PH, Chung TS, Shawn W, Lana I. Highly permeable double-skinned forward osmosis membranes for anti-fouling in the emulsified oil-water separation process. Environ. Sci. Technol. 2014;48:4537-4545.

6. Luo L, Han G, Chung TS, Weber M. Oil/water separation via ultrafiltration by novel triangle-shapetri-bore hollow fiber membranes from sulfonated polyphenylenesulfone. J. Membr. Sci. 2015;476:162-170.

7. Zhu Y, Wang D, Jiang L, Jin J. Recent progress in developing advanced membranes for emulsified oil/water separation. NPG Asia Mater. 2014;6:e101.

8. Ohya H, Kim JJ, Chinen A, et al. Effects of pore size on separation mechanisms of microfiltration of oily water using porous glass tubular membrane. J. Membr. Sci. 1998;145:1-14. 
9. Hua FL, Tsang YF, Wang YJ, Chan SY, Chua H, Sin SN. Performance study of ceramic microfiltration membrane for oily wastewater treatment. Chem. Eng. J. 2007;128:169-175.

10. Lobo A, Cambiella Á, Benito JM, Pazos C, Coca J. Ultrafiltration of oil-in-water emulsions with ceramic membranes: Influence of $\mathrm{pH}$ and crossflow velocity. J. Membr. Sci. 2006;278:328-334.

11. Rajasekhar T, Trinadh M, Babu PV, Sainath AVS. Oil-water emulsion separation using ultrafiltration membranes based on novel blends of poly (vinylidene fluoride) and amphiphilic tri-block copolymer containing carboxylic acid functional group. J. Membr. Sci. 2015;481:82-93.

12. Yuliwati E, Ismail AF. Effect of additives concentration on the surface properties and performance of PVDF ultrafiltration membranes for refinery produced wastewater treatment. Desalination 2011;273:226-234.

13. Gutierrez G, Lobo A, Benito JM, Coca J, Pazos C. Treatment of a waste oil-in- water emulsion from a copper-rolling process by ultrafiltration and vacuum evapora-tion. J. Hazard. Mater. 2011;185:1569-1574.
14. Mohammadi T, Esmaeelifar A. Wastewater treatment of avegetable oil factory by a hybrid ultrafiltration-activated carbon process. J. Membr. Sci. 2005;254:129-137.

15. Yahiaoui O, Lounici H, Abdi N, Drouiche N, Ghaffour N, Pauss A. Treatment of olive mill wastewater by the combination of ultrafiltration and bipolar electro-chemical reactor processes. Chem. Eng. Process. 2011;50:37-41.

16. Matos M, García CF, Suárez MA, Pazos C, Benito JM. Treatment of oil-in-water emulsions by a destabilization/ultrafiltration hybrid process: Statistical analysis of operating parameters. J. Taiwan Inst. Chem. Eng. 2016;59:295-302.

17. Pulido JMO, Stoller M, Palma LD, Ferez AM. On the optimization of a flocculation process as fouling inhibiting pretreatment on an ultrafiltration membrane during olive mill effluents treatment. Desalination 2016;393:151-158.

18. Karhu M, Kuokkanen T, Rämö J, Mikola M, Tanskanen J. Performance of a commercial industrial-scale UF-based process for treatment of oily wastewaters. J. Environ. Manage. 2013;128:413-420. 